\title{
0 género está em cena A generosidade da partilha crítica e da disseminação da teoria
}

Filomena Louro

Ana Gabriela Macedo e Francesca Rayner (Orgs.), Género, cultura visual e performance: Antologia crítica, Vila Nova de Famalicão, Centro de Estudos Humanísticos da Universidade do Minho \&t Edições Húmus, 2011, 185 pp.

No título desta nova antologia está omisso um valor que não sendo tecnicamente um equipamento crítico, está patente na sua introdução e no trabalho de colecção e edição destas onze traduções, constituindo o primeiro motivo por que partilho de forma entusiástica a leitura desta obra. É esse valor a generosidade da partilha.

Recentemente editada pela Húmus, este pequeno volume contém em si objectivos que o tornam de particular interesse para os estudiosos da teoria de performance, do fenómeno teatral inscrito numa vasta rede de saberes transversais que enriquecem e fertilizam esse estudo.

0 segundo volume de uma colecção de antologias patrocinada pelo Centro de Estudos Humanísticos da Universidade do Minho ${ }^{1}$, esta colectânea releva o desafio de tornar acessivel a um vasto público de língua portuguesa uma selecção criteriosa de textos fundadores e intervenientes no estabelecer do debate de áreas transversais e específicas no estudo de género, da performance e da cultura visual.

Este trabalho é o segundo produto da colaboração de uma equipa de investigação transdisciplinar que nos ofereceu anteriormente a muito recomendada obra Género, identidade e desejo: Antologia crítica do feminismo contemporâneo (2002).

Ana Gabriela Macedo, coordenadora desta equipa, declara na Introdução que o objectivo deste projecto é o de, através destas publicações, constituir um incentivo à divulgação científica, à difusão e debate informado de

0 primeiro volume desta colecção foi dedicado a Estética e teorias de arte, organizada por Vitor Moura em 2009.

Filomena Louro

é Professora Associada

do Departamento de Estudos Ingleses e Norte Americanos da Universidade do Minho. temas pertinentes para a compreensão das Novas Humanidades.

Esta partilha do seu entusiasmo crítico e teórico com a comunidade académica de língua portuguesa nas áreas de estudos feministas, da performance e das artes visuais é uma aposta segura porque na sua génese encontramos já esse alargar da rede de partilha e debate crítico que estimula, congrega, informa e debate. Esta experiente equipa de investigadoras convida à colaboração novas investigadoras, estudantes e tradutoras que assim criam já de raiz, uma comunidade de debate crítico e teorizante que só pode ir crescendo e consolidando conceitos, propondo com o seu trabalho - solidamente fundamentado

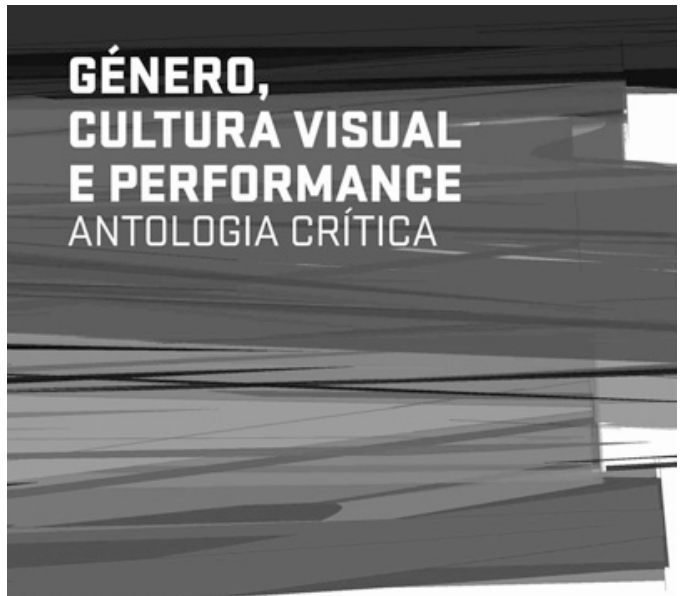

02

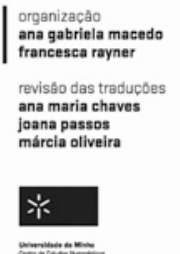

hthatas

- novos projectos criticamente bem estruturados. Ao traze para este trabalho a colaboração de estagiárias de tradução - que enfrentaram em primeiro voo profissional a dificuldade de exegese de uma colecção de textos densamente críticos e teóricos - proporcionou a estas jovens licenciadas o que se pode chamar um bom começo. Auspicioso para elas como primeiro trabalho, independentemente do posterior alinhamento critico necessário à unidade do volume.

0 objectivo da antologia na divulgação e partilha destes textos é, como foi dito, proporcionar um debate criativo e estimulante para o público, que já se pode senti na organização dos próprios temas e textos escolhidos: o índice oferece um percurso crítico de extrema relevância e contemporaneidade, independentemente das datas de publicação dos originais.

Fica patente também o objectivo pedagógico, reflexo do percurso de investigação da equipa organizadora - as professoras Ana Gabriela Macedo e Francesca Rayner que investigam para criar e partilhar, problematizar e dar a saber, como quem dá a comer. É aqui que fundamento o particular carácter generoso deste projecto, que se propõe contribuir para a "definição de áreas prioritárias 
nas Humanidades hoje, na exigência dos saberes transversais e nas relações interdisciplinares entre as artes", como fica expresso na página nove da introdução. Segundo a mesma académica, a escolha destes textos justifica-se por cada um constituir " um marco histórico e epistemológico no quadro da disciplina específica a que se reporta" (Ibid:: 9)

0 primeiro texto de Rosemary Betterton "Olhar feminista: olhar o feminismo" (2003) abre o debate ao problematizar a produção de sentido na cultura visual. Oferece uma conclusão muito positiva ao apreciar o efeito do impacto da crítica feminista na produção dos equipamentos críticos de massas, ao verificar que as suas alunas já os utilizam de forma imanente, como práticas de visionamento do século XXI.

De Marvin Carlson podemos ler "O que é a performance?", de novo um texto crítico eminentemente pedagógico. Carlson estabelece de uma maneira lúcida os limites do debate sobre o conceito de performance, ao mesmo tempo que integra a sua validade e utilidade no contexto do ser pós-moderno, e este no contexto da actual relação da arte com o poder e com a busca de identidades em todas as áreas.

Para os que entre nós pensam e problematizam a articulação da herança brechtiana com o desenvolvimento do pensamento feminista e o seu entrosamento na prática performativa e na teoria teatral latu sensu, o texto de Elin Diamond - "Teoria brechtiana / Teoria feminista: Para uma crítica feminista géstica" (1996) - abre pistas muito criativas. Identificando a destrinça do olhar que faz a diferença feminista, e esclarece: "nós feministas da área de estudos teatrais e dramáticos preocupamo-nos mais com a crítica do olhar do que com a intervenção brechtiana que assinala a forma de desmantelar o olhar" (p. 35). Daqui evolui a proposta de uma crítica feminista especificamente teatral a "critica géstica". Revendo algumas contribuições de marxistas sobre o debate de teoria versus prática, conclui este preâmbulo com a lapidar súmula de Blau sobre o assunto que não resisto a citar: " o Teatro é teoria, ou uma sombra dela... No acto de ver, está já inscrita uma teoria" (Blau1982:1) (p. 36). Desenvolvendo os binómios Género/ $V$-effekt, Diferença sexual/ distanciamento, Elin Diamond valoriza o facto de a linguagem do género ser baseada na diferença, resumindo a chave para a teoria do

distanciamento de Brecht numa determinação de "[lembrar] as diferenças em vez de se conformar com representações estáveis de identidade e ligar essas diferenças a 'políticas práticas'" (p. 40). Para exemplificar o seu conceito de crítica feminista géstica, Elin Diamond propõe um exemplo da obra da autora lactora Aphra Behn, ilustrando com humor e pertinência a primeira manifestação do conceito Gestus, num espaço que recupera a especificidade sexual, histórica e teatral.

Outros textos usam o âmbito da manifestação teatral, seja na dança, teatro ou perfomance para exemplificarem o conceito de que o género é uma identidade instável e ténue constituída através de uma "repetição estilizada de actos" como no texto de Judith Butler "Actos performativos e constituição de género", ou como no ensaio de Janet Wolff "Recuperando a corporalidade: Feminismo e politica do corpo" (2003) equacionando a prática do feminismo com as repressivas práticas retóricas que regulam o corpo na dança ou outras performances.

Tomando emprestado o título de Sônia Maluf ${ }^{2}$, podemos dizer que "o corpo está em cena", para sublinhar a relevância de um outro texto desta antologia que explora a corporalidade numa outra arte, o cinema, submetendo esse meio criativo ao olhar escrutinador de Laura Mulvey em "Prazer visual e cinema narrativo" (1999). Numa análise de forte pendor psicanalítico, Mulvey foca o fascínio da forma humana e a maneira de a fruir através das estruturas narrativas filmicas e das condições de exibição que dão a ilusão de espreitar um mundo privado. A autora identifica um "determinante olhar masculino" e uma fetichização da imagem da mulher e do corpo feminino através das teorias do olhar. Ao descodificar os códigos cinemáticos que criam um olhar, um mundo e um objecto a partir de uma escopofilia masculina e voyeurista, podemos seguir a argumentação através de exemplos da obra filmica de Hitchcock, entre outros realizadores, e de figuras maiores da tela que nos permitem apreciar como são determinados os modos em que a mulher deve ser olhada, constituindoa como imagem, e ao homem como detentor do olhar voyeurista-escopofilico.

Seguem-se textos que focam mais especificamente as artes visuais como "A modernidade e os espaços da feminilidade", um texto de Griselda Pollock de 1988, questionando, de uma maneira que fez escola, os trabalhos consagrados da arte moderna que dirigem o seu olhar e delimitam o seu escopo na área da sexualidade, enquanto bem comercial, e continua a suscitar debate quando inquire qual a relação entre sexualidade e modernismo, trazendo ao debate as obras de Monet, Manet pela mão do estudo de Tim Clark, e também as obras de Renoir e Picasso.

Dois textos abordam o conceito de arte/cultura como sistema, do seu aprovisionamento em espaços constituídos em templos de arte ou seus cofres-fortes, os museus. Carol Duncan no seu texto " 0 museu de arte moderna" (1998) questiona a politica de aquisição e a função social desempenhada por instituições como o MoMA, ao analisar a presença de quadros de mulheres que, pela sua exibição, "masculinizam" o espaço museológico, requerendo assim sobre este o mesmo tipo de exercício crítico que Mulvey já desenvolvera para o visionamento da mulher no cinema. Neste caso as obras da coleção que Carl Duncan analisa são a emblemática Les demoiselles d'Avignon e Woman I de Wilhelm de Kooning.

James Clifford no seu artigo " Coleccionando arte e cultura" contrapõe a visão, leitura e interpretação que dois tipos diferentes de museu concitam e impõem sobre os objectos que exibem, trazendo sobre eles designações e valorações diversas. 0 museu etnográfico e o museu de
${ }^{2}$ Uma obra que analisa representação do corpo nas culturas contemporâneas como recipiente da produção simbólica ou das representações sociais. 


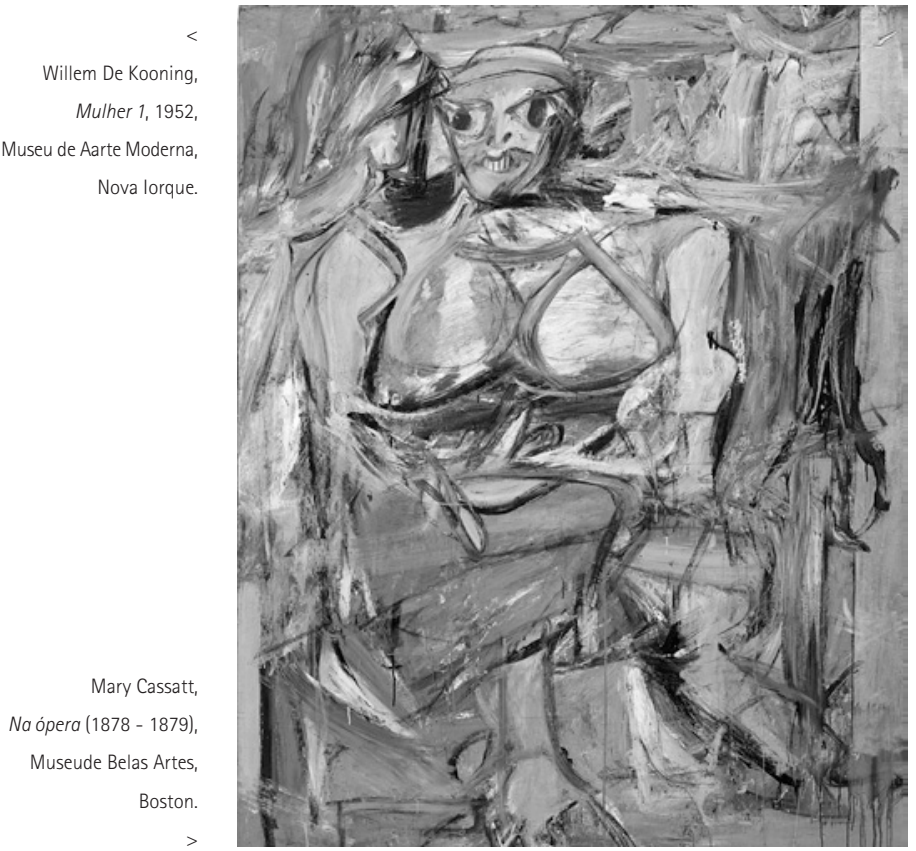

arte constroem aparelhos significantes que determinam e condicionam o olhar do público, mas estes códigos não são imutáveis. A atestá-lo estão os exemplos dos percursos que certos artefactos realizaram ao longo da sua vida em acervo museológico, de uma instituição para outra conforme vai variando o olhar interpretativo que os define. Neste percurso Clifford analisa a evolução dos movimentos etnográficos e não etnográficos na apreciação da arte ou objectos "não-ocidentais". Seguindo o exemplo de Fredric Jameson que adapta o quadro semiótico de Greimas aos objectivos da crítica cultural, Clifford apresenta um mapa onde identifica quatro zonas semânticas: a das obrasprimas autênticas, a zona dos artefactos autênticos, a zona das obras-primas inautênticas e a zona dos artefactos nãoautênticos (figura V, p. 157), identificando assim áreas de tráfego dentro do sistema. Toda esta reflexão e análise de diversos museus acaba por propor uma conclusão: "As categorias do belo, do cultural e do autêntico mudaram e continuam em mudança".

Num exercício de aplicação, este texto levou-me a olhar para a minha modesta colecção de boquilhas, artefactos que contemplo como estilizados exemplos da sofisticação do acto de fumar levado ao máximo requinte, enquadrado num envolvimento que marca socialmente 0 gesto e o seu actor, as peças em si que foram produzidas, esculpidas algumas, compradas ou oferecidas, com diferentes valorações pecuniárias e estéticas, para depois passarem ao mercado de curiosidades, artefactos autênticos que podem já ter tido uma existência de obras-primas, mas que, no actual contexto social, não passam de registo de um comportamento desvalorizado, o do fumador.

Esta antologia, que nos convida a uma estimulante viagem crítica, encerra com um excelente texto de Andreas Huyssen: "A cultura de massas como mulher. 0 'outro' do modernismo" (1986). Partindo de Madame Bovary, ávida consumidora de literatura inferior, por oposição à imagem nobre de Flaubert como produtor de alta literatura, Huyssen segue o percurso da cultura de massas como "o subtexto do projecto modernista" (p. 171). Sublinha como o discurso político, psicológico e estético nos finais do século XIX vê

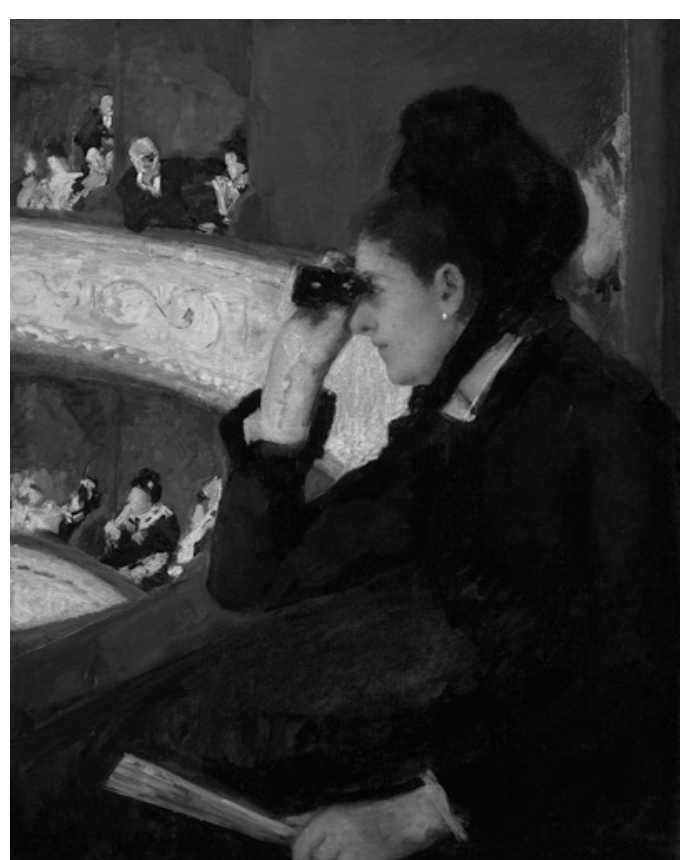

a cultura de massas e as massas como femininas, ao passo que a cultura de elite e das elites era considerada uma actividade masculina. Ao longo do século XX, mesmo o discurso das vanguardas históricas e estéticas foi tão patriarcal, misógino e machista como o discurso do modernismo, só vindo a diminuir com o "declínio do próprio modernismo" (p. 184). Questionando a "outridade" do feminino no contexto da cultura de massas, fica claro no postulado de Huyssen que é o desmantelamento do cânone modernista nos anos Sessenta e essa intervenção "outra" das mulheres ascendendo à produção de arte de elite o que provoca o desmantelamento deste padrão de pensamento.

Formalmente a composição deste volume dá relevo particular às obras de referência, destacando-as. Este exercicio académico, pedagógico e teorizante recebeu já a montante eco dos autores dos textos que graciosamente permitiram a sua tradução. Tenho a convicção de que a circulação dos textos escolhidos pelas professoras Ana Gabriela Macedo e Francesca Rayner aqui oferecidos vão contribuir para tornar acessivel a estudantes e investigadoras/es um estimulante conjunto de textos basilares do moderno pensamento crítico feminista.

\section{Referências bibliográficas}

BLAU, Herbert (1982), Take up the Bodies: Theatre at the Vanishing Point Urbana, University of Illinois Press.

DUNCAN, Carol Duncan (1998), "The Modern Art Museum", in Nicholas

Mirzoeff ( ed), Visual Culture Reader, Londres e Nova York, Routledge, pp. 85-93.

MACEDO, Ana Gabriela (Org.) (2002), Género, identidade e desejo: Antologia critica do feminismo contemporâneo, Lisboa, Cotovia.

MULVEY, Laura Mulvey (1999), "Visual Pleasure and Narrative Cinema", in Jessica Evans and Stuart Hall (ed), Visual Culture : the Reader, Londres, Sage Publications com a Open University, Thousand Oaks, Nova Deli, pp 94-99.

WOLFF, Janet (2003), "Reinstating Corporeality, Feminism and Body Politics", in Amelia Jones (ed.) The Feminist and Visual Culture Reader, Londres e Nova York, Routledge, pp. 414-325. 